\title{
Successful knowledge transfer within offshore supplier networks: a case study exploring social capital in strategic alliances
}

\author{
Joseph W Rottman \\ College of Business Administration, University of Missouri-St. Louis, St. Louis, MO, USA
}

Correspondence:

JW Rottman, College of Business Administration, University of Missouri-St. Louis, One University Boulevard, 8001 Natural

Bridge Road, St. Louis, MO 63121-4400, USA.

Tel: + 1314516 6288;

Fax: +1314 516 6827;

E-mail: rottman@umsl.edu

\begin{abstract}
Managing a global network of suppliers presents considerable challenges for large multinational corporations. Chief among these is how to effectively transfer knowledge among members of strategic alliances while maintaining tight control over intellectual property. This paper highlights the efforts of a Fortune 100 manufacturing firm (hereafter US Manufacturing) and its management of global IT suppliers. Using a social capital framework developed by Inkpen and Tsang (2005), we explore the supplier network at three levels (structural, cognitive, and relational) and present eight proven practices for creating, managing, and exploiting social capital within strategic alliances. The Inkpen and Tsang framework examines the linkages between knowledge transfer and social capital for three network types: intracorporate networks, strategic alliances, and industrial districts. We use the strategic alliance of US Manufacturing and its suppliers to illustrate salient social capital dimensions and the conditions and practices that facilitated knowledge transfer. These practices enabled US Manufacturing to improve knowledge transfer, decrease development costs, shorten cycle time, increase the quality of developed deliverables, quickly respond to changes in the regulatory environment, and, most importantly, build strong, strategic relationships with its suppliers.

Journal of Information Technology (2008) 23, 31-43. doi:10.1057/palgrave.jit.2000127

Keywords: offshore outsourcing; social capital; knowledge transfer; strategic alliances; embedded software
\end{abstract}

\section{Introduction}

$\mathbf{T}$ his case illustrates the importance of social capital and knowledge transfer for successfully outsourcing software development. Researchers have shown that the offshore outsourcing literature is contradictory in reporting the outcomes of offshore outsourcing engagements (Lacity and Rottman, 2008). Many researchers highlight the difficulties in successfully outsourcing IT (Information Technology) work:

- A Gartner survey found a 50\% failure rate for offshore outsourcing initiatives (Aron and Singh, 2005).

- A survey of 204 software developers found that $46 \%$ viewed the work performed by the offshore teams to be of poor quality (Carter, 2006).

- Ventoro's survey of over 5200 executives from North America and Europe found that nearly $28 \%$ of respondents experienced cost increases and another $25 \%$ did not generate any cost savings with offshore outsourcing (Hatch, 2005).

While global sourcing is technically possible because work that can be digitized can be moved, there are many managerial challenges. One common complaint was that overall cost savings was less than anticipated due to the high transaction costs associated with finding suppliers (or erecting captive centers), coordinating, and monitoring work done offshore. ${ }^{1}$ Other common complaints were that quality was initially poor, delivery was slow, and personnel issues such as high supplier turnover interfered with success (Lacity and Rottman, 2008). 
Conversely, successes in the effort to offshore IT work are also reported in practitioner outlets:

- A survey of 38 companies in North America and Europe, of which $85 \%$ were involved in offshore outsourcing of IT work, found that $89 \%$ were satisfied with their offshore outsourcing initiatives (Beal, 2004).

- A DiamondCluster survey of 210 buyers found that offshore outsourcing satisfaction rates were high, but falling from 79 to $62 \%$ between 2004 and 2005 (DiamondCluster, 2005).

This case highlights how one firm was able to successfully outsource the development of embedded software. Success, however came only in the firm's second attempt at offshore outsourcing - their first attempt failed. Their success in the second attempt can be attributed in large part to the paying of significant attention to knowledge transfer processes and the creation and cultivation of social capital.

Social capital is simply the idea that knowledge and resources are exchanged, work gets done, and value is created through social relationships. In the context of outsourcing who the supplier knows in the client organization is the key to ensuring what value the supplier delivers. Conversely, who the client knows in the supplier organization is often a key to ensuring which supplier resources will be devoted to the client's account to ensure value. Research suggests that once social capital is built, many benefits follow. These benefits include increased efficiency, more cooperative behavior, higher levels of trust, less need for costly monitoring, and most importantly - increased innovation (Nahapiet and Ghoshal, 1998).

This case details the efforts of the Software Center of Excellence (SCE) within a US Manufacturing firm and its interactions with its network of suppliers. It demonstrates the need to integrate the suppliers' development teams into the internal teams as well as the necessary processes and frameworks to facilitate the establishment of social capital and the transfer of knowledge between members of a strategic alliance. This case utilizes the framework developed by Inkpen and Tsang (2005) to categorize and describe eight practices US Manufacturing used in its relationship with its suppliers.

This paper proceeds as follows. The first section describes the prior literature on social capital and knowledge transfer. It is followed by the research methodology, the case background, and a description of the social capital dimensions and practice used within those dimensions by US Manufacturing. It concludes with implications for both research and practice.

\section{Literature review: social capital and knowledge transfer}

The Inkpen and Tsang (2005) model represents the theoretical framework we used to classify the practices US Manufacturing employed. This model, described below, is closely linked with many research areas. Namely, the bodies of literature related to trust, knowledge transfer, social capital, cross-cultural issues, and geographically dispersed teams are clearly relevant. Specifically, researchers have addressed the role of trust (Politis, 2003; Chowdhury, 2005), trust and geographically dispersed teams (Jarvenpaa et al., 1998; Trompenaars and Hampden-Turner, 1998; Hofstede,
2001), and knowledge transfer (Orr, 1996; Tsoukas, 1996; Hansen, 1999; Argote and Ingram, 2000; Levin and Cross, 2004; Rottman, 2006; Rottman and Lacity, 2006b). While researchers have focused on various salient issues of group social capital (Oh et al., 2006), the effects of involuntary employee turnover (Shaw et al., 2005), voluntary turnover (Dess and Shaw, 2001), the creation of knowledge at the individual level (McFadyen and Cannella, 2004), absorptive capacity (Tsai, 2001), and external knowledge acquisition (Anand et al., 2002), this paper focuses on the creation of social capital and knowledge transfer within a strategic alliance.

Adapting Nahapiet and Ghoshal's (1998) model which identified social capital and combinations and exchanges of intellectual influences on the creation of new intellectual capital, Inkpen and Tsang (2005) use three types of organizational groupings to describe the social capital dimensions and the facilitating conditions for knowledge transfer. They analyzed the structural, cognitive, and relational dimensions of social capital across three network types: intracorporate networks, industrial districts, and strategic alliances. To properly understand how the relationship between US Manufacturing and its suppliers fits into the strategic alliance category, a brief description of the other network types is appropriate.

Inkpen and Tsang describe three types of networks, intracorporate networks, strategic alliances, and industrial districts. They define an intracorporate network as 'a group of organizations operating under a unified corporate identity, with the headquarters of the network having controlling ownership interest in its subsidiaries' (2005: 148). The salient characteristics of this type of network are the clear hierarchies and centralization of decision-making. In contrast to the formality of the intracorporate network, an industrial district 'consists of a network of producers, supporting organizations and a local labor market' (2005: 149). These firms would share a geographical area or market segment.

An industrial district consists of independent firms sharing similar goals and geographic areas who utilize similar producers, pull from the same labor pool and target similar markets (Inkpen and Tsang, 2005).

Strategic alliances however, exist between firms that do not necessarily share a formal hierarchy or a geographical area and market segment. A strategic alliance 'can be formed by firms located in different positions or in the same position in the value chain' Inkpen and Tsang (2005). Firms enter into a strategic alliance voluntarily with the idea of a common benefit resulting from the arrangement.

It is in the context of a strategic alliance that we adopt Inkpen and Tsang's definitions of both social capital and knowledge transfer. Based on both Inkpen and Tsang's definition of a strategic alliance and prior research related to alliances and outsourcing engagements, the relationship US Manufacturing had with its suppliers constitutes a strategic alliance. As Table 1 shows, despite the relatively small scale of the SCE's relationship with its suppliers, prior definitions of alliances and strategic alliances validate the use of a strategic alliance framework in this case. Additionally, as mentioned in case discussion section below, the relationships between US Manufacturing and its suppliers which continue to increase in size and complexity, allowed 
Table 1 : Representative research studies utilizing strategic alliances

\begin{tabular}{|c|c|}
\hline Author(s) & Support for use of strategic alliance in outsourcing relationships \\
\hline $\begin{array}{l}\text { Zineldin and } \\
\text { Bredenlow } \\
\text { (2003) }\end{array}$ & $\begin{array}{l}\text { 'Strategic alliances are viewed broadly as agreements among firms to work together to attain some } \\
\text { strategic objective. This definition accommodates the myriad arrangements that can rage from } \\
\text { handshake agreements to licensing, mergers, outsourcing and equity joint ventures. Such cooperation } \\
\text { may take the form of ... research and development partnerships.' } \\
\text { 'Outsourcing is a typical form of strategic alliance. It is about "make or buy."' }\end{array}$ \\
\hline $\begin{array}{l}\text { McFarlan and } \\
\text { Nolan (1995) }\end{array}$ & $\begin{array}{l}\text { 'Alliances allow a firm to leverage a key part of the value chain by bringing in a strong partner that } \\
\text { compliments its skills.' }\end{array}$ \\
\hline $\begin{array}{l}\text { Koka and } \\
\text { Prescott (2002) }\end{array}$ & 'Firms resort to strategic alliances to access capabilities necessary for competitive advantage.' \\
\hline Gulati (1995) & $\begin{array}{l}\text { 'Organizational members of the partner firms [in alliances] work together directly from their own } \\
\text { organizational confines. Nonequity alliances include unidirectional agreements, such as licensing, } \\
\text { second-sourcing, and distribution agreements, and bidirectional agreements such as joint contracts } \\
\text { and technology exchange agreements.' }\end{array}$ \\
\hline $\begin{array}{l}\text { Tiwana and } \\
\text { Keil (2007) }\end{array}$ & $\begin{array}{l}\text { '[Strategic alliances] allow outsourcing firms to specialize deeper in their domain of core competence } \\
\text { without being distracted by non-core activities.' } \\
\text { 'A related motivation for forming outsourcing alliances is to access specialized knowledge that is so } \\
\text { removed from the outsourcer's core activities that it might simply not exist in the outsourcing firm.' }\end{array}$ \\
\hline $\begin{array}{l}\text { Inkpen and } \\
\text { Tsang (2005) }\end{array}$ & $\begin{array}{l}\text { 'A strategic alliance is a group of firms entering into voluntary arrangements that involve exchange, } \\
\text { sharing or co-development of products, technologies or services. The last two decades have witnessed } \\
\text { a proliferation of strategic alliances among firms as a result of technological development and } \\
\text { globalization.' }\end{array}$ \\
\hline
\end{tabular}

US Manufacturing to meet regulatory deadlines, develop new products quicker and more efficiently, better manage its talent pipeline and reduce development costs.

Building on the work by Nahapiet and Ghoshal (1998), Inkpen and Tsang define social capital as 'the aggregate of resources embedded within, available through, and derived from the network of relationships possessed by an individual or organization' (Inkpen and Tsang, 2005). In the context of the US Manufacturing case, the connection between US Manufacturing and its suppliers represents a 'social capital resource' belonging to both firms. It is this idea that the connection itself between a supplier and a customer has an exploitable value that was missing in US Manufacturing's first offshore effort. The realization of the value and the practices employed to harness that value was a key success factor in US Manufacturing's second attempt offshore.

Argote and Ingram define knowledge transfer as the 'process through which one network member is affected by the experience of another. Knowledge transfer manifests itself through changes in knowledge or performance of the recipient unit' (Argote and Ingram, 2000: 151). In the context of a strategic alliance, 'alliances provide opportunities to create redeployable knowledge such as technical knowledge or market knowledge' (Inkpen and Tsang, 2005). The next section of the paper details the research method.

\section{Research methodology}

This research emerged over two years, involving formal interviews, document collection, informal interactions, interpretation of participants' interviews, and participant feedback on data interpretation. Initial contact with US Manufacturing was made at a large Indian supplier's executive summit involving their 20 largest and most prestigious clients. This initial meeting resulted in a site visit to US manufacturing's world headquarters, tours of the manufacturing facilities, introduction to, and interviews with, on-site supplier personnel, site visits at the Indian supplier's development center in Bangalore, India and follow-up interviews with US Manufacturing after the supplier interviews. This research is 'interpretative' in that we attempted to understand phenomena through the meanings participants assigned to them (Burrell and Morgan, 1979; Orlikowski and Baroudi, 1991; Walsham, 1995; Klein and Myers, 1999).

Using an interpretive field study approach as described by Klein and Myers (1999), interviews were conducted with three members of the SCE, including the Manager of the SCE, a Six Sigma Blackbelt and the Engineering Supervisor. Both the Six Sigma Blackbelt and the Engineering Supervisor reported directly to the Manager of the SCE. An interpretive methodology was used to gain knowledge of the reality of US Manufacturing's offshore engagements 'through social constructions such as language, consciousness, shared meanings, documents, tools and other artifacts' (Klein and Myers, 1999: 69).

Additionally, to understand the suppliers' views, interviews were conducted in US Manufacturing's headquarters with the supplier's on-site engagement manager as well as subsequent interviews with 10 members of US 
Manufacturing's largest offshore partner in Bangalore. Supplier participants included: the Vice President - Outsourcing Solutions, Associate Vice President of the Delivery Center, the Group Project Manager, Senior Project Managers and members of the delivery team which partner with the SCE at US Manufacturing.

Interviews with all 14 participants were tape-recorded and the interviews with the SCE staff and on-site engagement manager were transcribed and analyzed. Recordings of the interviews with the supplier's employees in Bangalore were not transcribed; however, copious notes were taken during the interviews and the recordings were listened to multiple times with additional notes being taken. In total, approximately $20 \mathrm{~h}$ of interviews were conducted. Additionally, the SCE provided significant documentation including service level agreements, letters of engagement, internal quality assurance reports, internal metrics and performance analysis, access to the human resource system used to track suppliers' employees and review of future staffing models.

\section{Detailed case background}

US Manufacturing is one of over 20 US customer firms studied as part of a larger project that focuses on the lessons learned by US firms who are engaged in offshore development of software (Rottman and Lacity, 2004; Rottman and Lacity, 2006a). Among the over 20 US customer organizations studied in this project, US Manufacturing showed the most strategic use of knowledge transfer. Before achieving strategic advantage with offshore outsourcing, however, US Manufacturing failed in its initial offshore initiatives. After diagnosing the causes of its initial failures, US Manufacturing remedied the supplier relationships with new structural, cognitive, and relational practices. These practices, which we have analyzed through the theoretical lens of social capital, highlight the importance of actively designing practices to build social capital to ensure successful strategic alliances.

US Manufacturing is a Fortune 100 manufacturer of industrial equipment with over 75,000 employees spread across 20 countries. The successful knowledge transfer practices and attention to social capital highlighted in this article are centered within US Manufacturing's Six Sigmacertified SCE. The SCE at US Manufacturing employs approximately 150 people and has an annual IT development spend of approximately $\$ 32$ million. The members of the SCE are responsible for the development and deployment of embedded software systems that are highly integrated into the manufacturing and operation of US Manufacturing's core products.

The SCE began its offshore journey in late 2000 with the hope of taking advantage of the labor arbitrage available offshore. With the primary goal of saving money on development costs, they selected small projects to begin their offshore engagements. A small pilot project (two offshore employees) integrating a new Global Positioning System (GPS) steering system into one of their larger product lines currently in production is indicative of the fact that in the first round of offshore outsourcing, US Manufacturing failed to invest in the processes and practices needed to build social capital and improve knowledge transfer.

For this project, US Manufacturing chose a large Indian supplier and placed all employees offshore to take greatest advantage of the labor rates. Specifically, this project required the offshore supplier to design and create the embedded software intended to control the steering systems and interface with the GPS satellites. The project involved new software tools, interface systems and processes for both the SCE and the supplier. Primarily due to the fact that knowledge transfer was an afterthought, this project failed to produce any of the deliverables outlined in the statements of work and was ultimately pulled back in house and completed well behind schedule and over budget.

According to the Engineering Supervisor,

It didn't succeed. We would get something back and it didn't do what we wanted it to do and we would have to redo the whole thing. We weren't very good at being outsourcers and the model of throwing a document over the wall and having a supplier magically give us what we want in the end- it didn't and doesn't work.

The GPS project was indicative of the many failures US Manufacturing encountered which were in large part related to social capital knowledge transfer. Owing to the project delays, the need for extensive rework to correct inaccurate and incomplete applications, project timelines and budgets were not met and business sponsors were disappointed in the process. Looking back, the manager of the SCE and his staff underestimated the need for extensive domain knowledge transfer (product, process, and market) as well as their own expertise in managing an offshore project.

According to the Manager of the SCE,

We had to realize that our Indian vendors did not understand embedded software or even the equipment we manufacture. They didn't even know what our product looked like! Now we are spending considerable time on domain knowledge transfer and training.

Another indication that the first round failures could be traced to insufficient social capital and knowledge transfer occurred when the staff of the SCE compared those failed projects which engaged offshore suppliers with projects that utilized only onshore suppliers. The post mortem that staff undertook showed that domestic suppliers, due to their experience working with US Manufacturing, their proximity to business users and their ability to see the products in action lessened the need for social capital and fundamental knowledge transfer.

According to the Six Sigma Blackbelt,

We never considered how much knowledge our [onshore] suppliers brought to the table. Having worked with them for years, they already knew a lot about us and our systems. We underestimated the amount of interaction that took place between them and our users and other developers. There was a lot of information going 
back and forth that we did not see. When we went offshore, that couldn't take place and we then realized its importance.

Despite the failures, US Manufacturing did see some promise in offshore development. While the projects themselves were not completed, they were confident that the offshore developers might be able to reduce the project backlog if US Manufacturing was able to better share knowledge and expertise with the suppliers. Based on internal process improvements and some improvement of code late in the engagement, US Manufacturing decided to move forward with the offshore model. According to the Manager of the SCE,

I must admit it was a tough sell, but we started to put in place much better systems to monitor our offshore resources as well as our internal teams. Our first few projects and the Six Sigma journey taught us: 'if you can't count it, you can't improve it'. So after some retooling, we tried again.

In January 2004, the SCE used the lessons it learned and re-launched its offshore effort. Realizing the need for better knowledge transfer, the second attempt was more measured and thoughtful. The SCE realized that the knowledge transfer process for embedded software development was critically important. One way the SCE tried to meet this challenge relates to how the SCE structured the engagements. In the second attempt, most of the employees of the offshore suppliers would spend time on-site at US Manufacturing's headquarters prior to working on the outsourced projects. According to the Manager of the SCE,

What we saw was the benefit and real value of actually bringing those people here for a short time to bring them up to speed. Let them see how an application works and work right next to the team doing the development. That is the real benefit to the teaming aspect.

The first attempt showed US Manufacturing that they needed to spend considerable time and resources in the knowledge transfer phase. The creation of embedded software requires a specialized skill set and manufacturing domain knowledge. Embedded software is much different than traditional software. Embedded software is found in many devices: thermostats, cell phones, cars, elevators, etc. Embedded software is used when any device has to interact with its environment. The 'rules' for traditional software do not apply to embedded software. For example response time, speed, power consumption and correctly interfacing with the external environment are paramount. In addition to 'normal' coding skills, embedded software development requires additional skills not readily available in the offshore space. Inherent in the successful creation of embedded software is an intricate and detailed knowledge of the equipment that will house and interact with the software.

Considering the extensive knowledge transfer and training issues involved with embedded software development facing US Manufacturing, they identified the risks associated with employee turnover and the need to ensure continuity of service. To mitigate these risks, US Manufacturing arranged with their supplier to overlap the onshore presence of key personnel. The training sessions were initially delivered by US Manufacturing's architects and project leads to the supplier's project leads. These trained employees would typically remain on site at US Manufacturing for 6-18 months. However, the hourly onshore rates are typically 3-4 times as high as the offshore rates and the labor arbitrage deteriorates the longer the employees are on site. US Manufacturing's ultimate goal is to have a 20/80 ratio of supplier employees who are onshore $v s$ offshore and to outsource no more than $30 \%$ of the development. However, migrating the trained employees offshore to train offshore employees creates a talent and knowledge vacuum on-site and severs many professional and personal connections that were created. To address this issue, US Manufacturing overlapped the supplier's new onsite resource with the old one for between 3 and 6 months. While this approach is expensive, the two on-site employees were able to establish common frames of reference and transfer relationships and connections to the new employee. Additionally, the new employee is trained by the old employee, freeing up US Manufacturing's architects and project leads to engage in higher level activities. Once the old employee migrates offshore, they are then able to transfer the knowledge obtained during their on-site time to the offshore employees and capitalize and expand on the intense learning which took place on-site.

The supplier selection and engagement process was also much different in round two for US Manufacturing. The failures in round one showed US Manufacturing that it was critical to establish a long-range plan with the offshore suppliers and the communication of US Manufacturing's long-range strategy was necessary during the due diligence phase of the engagement. Specifically, the members of the SCE targeted firms that were willing to begin the process slowly knowing that the supplier would need to invest heavily in the knowledge transfer process to ensure success. In round two, US Manufacturing selected two large Indian suppliers that had already exhibited expertise in the embedded software market, primarily in the automotive industry. In addition, they selected a boutique firm that specialized in embedded software in the manufacturing market. This prior experience with the embedded software development process was a critical success factor that was overlooked in round one.

We really didn't understand how different we (embedded software development) were until we saw the failures in round one. We now know that our vendors need a very specialized skill set and we now know how to identify and test for those skills. We are much better at vendor selection and talent assessment.

The services of the two large suppliers and one boutique firm represented about $\$ 3.4$ million, or $10 \%$ of SCE's annual budget. These suppliers provided about 15 people on-site and 35 people off-site. The three engagements are all increasing in dollar value and headcount. 
The manager of the SCE summarized round two by stating:

I think we are now doing it right and the data we are gathering support that idea. Our vendors are not only providing a lower cost talent pool, but they are helping us strategically. We keep looking for ways to increase the engagements. Our costs are down, productivity is up, and the quality is as good, if not better than what we can do in house.

The successes found in round two were due in large part to the establishment of social capital and the benefits social capital on successful knowledge transfer between US Manufacturing and its suppliers. The next section details the dimensions of social capital and the practices US manufacturing employed.

\section{Social capital dimensions and SCE practices}

The practices utilized by the SCE at US Manufacturing are listed in Table 2 as they correspond to the social capital dimensions. This classification was made using the transcripts of the interviews as well as Inkpen and Tsang's description of the various dimensions.

Each dimension affects knowledge transfer differently and has differing facilitating conditions. 'The structural dimension of social capital involves the pattern of relationships between the network actors and can be analyzed from the perspective of network ties, network configuration and network stability' (Inkpen and Tsang, 2005: 152). The structural dimension within social capital relates to the boundaries that must be spanned in order for knowledge transfer to take place (Levina and Vaast, 2005). These boundaries may be spanned by network ties. 'The fundamental proposition of social capital theory is that network ties provide access to resources' (Nahapiet and Ghoshal, 1998: 252). However, in a strategic alliance, the amount of information passing through this boundary can lead to a divulging of proprietary intellectual property or an unbalanced relationship with one supplier. 'Ties provide the channels for information transmission, but the overall configuration of these ties constitutes an important facet of social capital that may impact the development of intellectual capital' (Nahapiet and Ghoshal, 1998: 252). This represents a significant risk for US Manufacturing.

To mitigate these risks while enhancing the network structure, US Manufacturing developed three practices for effective knowledge transfer.

Structural Dimension: Practice 1: Utilize multiple suppliers to enhance network ties and to increase social networks The SCE distributed work among three suppliers (two large and one boutique). While maintaining engagements with multiple suppliers did increase transaction costs and management overhead, the benefits included protection of intellectual property and the creation of a competitive environment to keep costs low and quality high.

The use of multiple suppliers created larger social networks thus increasing US Manufacturing's ability to both create social capital and manage knowledge transfer. While it may seem counter-intuitive that increasing the number of suppliers would increase the social capital between teams, the SCE found that exposure to divergent engagement models, vendors with different work processes and styles, and vendors with unique expertise, broadened the outlook of the internal employees. Specifically, internal teams were able to enhance their own skill sets and increase their levels of expertise and confidence by working with developers from multiple vendors.

The manager of the SCE concluded:

In our first try, we only used one vendor and we did not learn much from them and they did not help us. When we spread work out [across vendors], our processes improved as did the exposure of our internal people to multiple viewpoints. It also helped us to 'keep alive' multiple vendors - we were spreading the development around.

This practice is closely related to Structural Dimension Practice 2 in that intellectual property can be protected

Table 2 Social capital dimensions and SCE practices

\begin{tabular}{ll}
\hline Social capital dimension & SCE practice \\
\hline $\begin{array}{l}\text { Structural (Network ties and } \\
\text { configuration) }\end{array}$ & $\begin{array}{l}\text { 1. Utilize multiple suppliers to enhance network ties and to increase social networks. } \\
\text { 2. Increase network utilization and frequency and maintain multiple connections by } \\
\text { unitizing projects into small segments. }\end{array}$ \\
& $\begin{array}{l}\text { 3. Ensure knowledge retention and transfer by requiring supplier to have shadows } \\
\text { for key supplier roles. }\end{array}$ \\
$\begin{array}{l}\text { Cognitive (Shared goals and } \\
\text { culture) }\end{array}$ & $\begin{array}{l}\text { 4. Strengthen cultural understanding by visiting the offshore supplier and project } \\
\text { teams. }\end{array}$ \\
& $\begin{array}{l}\text { 5. Clarify goals by communicating the offshore strategy to all parties. } \\
\text { 6. Integrate the supplier's employees into the development team. } \\
\text { 7. Co-train internal employees and supplier employees to communicate goals and } \\
\text { increase cultural awareness. }\end{array}$
\end{tabular}


and the network enhanced by not only utilizing multiple suppliers but also unitizing the projects.

\section{Structural Dimension: Practice 2: Increase network utilization and frequency by unitizing projects into small segments}

The first part of the practice involved the unitization of tasks to be sourced. These tasks were typically $5-7$ business day activities that had clearly defined objectives and requirements. While the transactional overhead of this strategy was considerable, the Manager of the SCE claimed the transaction costs were more than recouped by such close monitoring:

In our first round [the failed attempt at offshore sourcing], projects were allowed to creep and the only people who saw the creep were the accounts payable people on our end and the accounts receivable people at the supplier. Now, each task has an owner and we watch the projects from a functional perspective, not an accounting perspective. By using this strategy, we are seeing much less re-work and the quality has improved considerably!

Considering the proprietary nature of the software the SCE developed, they faced an interesting problem: how to transfer enough knowledge to enable successful product development while protecting their trade secrets. To mitigate this risk, the SCE (1) unitized projects into small segments of work and (2) dispensed these segments among three offshore suppliers to effectively distribute the intellectual property. They viewed their intellectual property as a puzzle. By distributing small pieces among three suppliers, no one supplier can assemble the puzzle on their own (see Figure 1).

This model also created a system of both strong and weak network ties between teams. The strength of a tie is a continuum and is defined as 'a combination of the amount of time, the emotional intensity, the intimacy (mutual confiding), and the reciprocal services which characterize the tie' (Granovetter, 1973: 1361). In the case of US Manufacturing, the strong ties facilitated trust, reciprocal information exchange, and performance, while the weak ties facilitated the generation of new information. For example, an internal team working closely on a project with Supplier One would develop strong ties. Additionally, that team may also work peripherally with Supplier Two. This created a weak tie with Supplier Two which exposed the team to new techniques, tools and processes. While connections did not exist between suppliers, US Manufacturing teams did interact simultaneously with multiple suppliers, thus increasing network utilization, network ties, and the opportunity for knowledge transfer. As Hagedoorn et al. (2006) noted, a combination of strong and weak network ties can a positive impact on the firm which was the case with US Manufacturing.

This practice had important impacts on the knowledge transfer process. Specifically, by unitizing the work into small objects, the number of exchanges between US Manufacturing and its suppliers increased thus increasing the strength of the tie while creating multiple connections between them as well.

\section{Structural Dimension: Practice 3. Ensure knowledge retention and transfer by requiring suppliers to have shadows for key supplier roles}

To counteract the increased training costs associated with unitization of projects and the use of multiple suppliers, the SCE required suppliers to overlap key people in the engagement. This practice also helped to mitigate the risks associated with supplier employee turnover. (Unwanted supplier employee turnover was as high as $75 \%$ in some of the companies studied.) Employee turnover can have a destabilizing effect on a social capital network. As Inkpen and Tsang found, 'personnel turnover affects intracorporate knowledge sharing, which often takes place through formal or informal exchanges on an individual basis. Maintaining a stable pool of personnel within a network
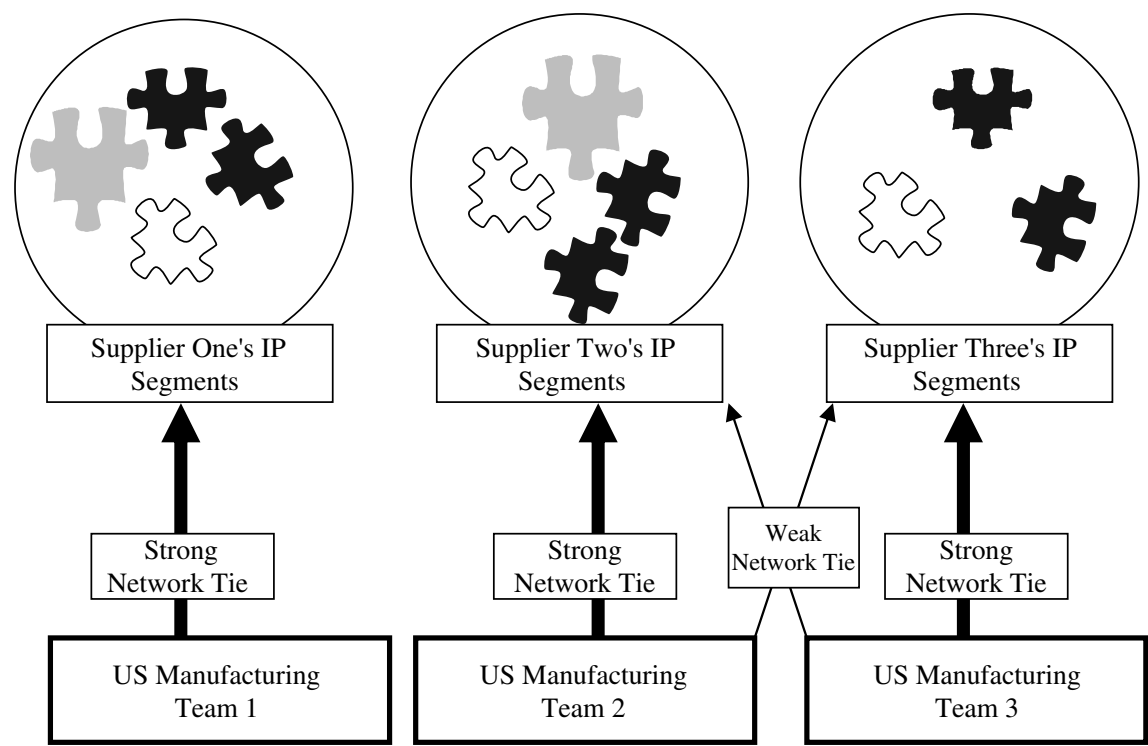

Figure 1 Intellectual property and network ties. 
can help individuals develop long-lasting interpersonal relationships' (2005: 156).

To help maintain the stability of the network, the SCE required that trained supplier employees remain on the account for at least 1 year after training or the supplier would incur the costs of training a replacement. This facilitated knowledge transfer because relationships were maintained and network stability increased.

For key supplier roles such as project leads or architects, the need to ensure continuity was even greater. US Manufacturing required suppliers to provide shadow employees for key on-site supplier roles. Depending on the role, the required shadowing period was 3-6 months. This overlap period had two major social capital and knowledge transfer benefits. First, the knowledge transfer was done predominately between the supplier's employees, thus freeing up the SCE's valuable architects and leads. Second, the incumbents were able to ease the impending transition by introducing their replacements to US Manufacturing's business units and staff and subsequently transferring more social aspects of the arrangement. This helped to maintain the social contacts and connections that were created during the engagement. According to the engineering supervisor:

Once we started overlapping the liaisons, our customers felt much better about rolling people off the project. The outgoing liaisons made our job much easier since they took their initial training and subsequent learning and were able to convey it to their replacement much, much better than we can.

Figure 2 shows the relationship between the supplier's on-site projects leaders and the offshore team. The shadowing allowed the social capital (both personal and professional) to be maintained when the supplier's employee then shared the knowledge with the offshore development team members.

Specifically, the Senior Project Manager for US Manufacturing's large Indian supplier extolled the impacts of employee shadowing,

It was nice to share experiences both professional and personal with other managers who had been on-site. We would have meetings with each other and talk about projects and the people involved. Even though I never met [US Manufacturing's] teams in person, talking to my counterpart here in India helped me learn processes and personalities.

\section{Cognitive dimension practices}

The cognitive dimension of Inkpen and Tsang's framework encompasses the idea of shared cultural goals and vision. 'Shared goals represent the degree to which network members share a common understanding and approach

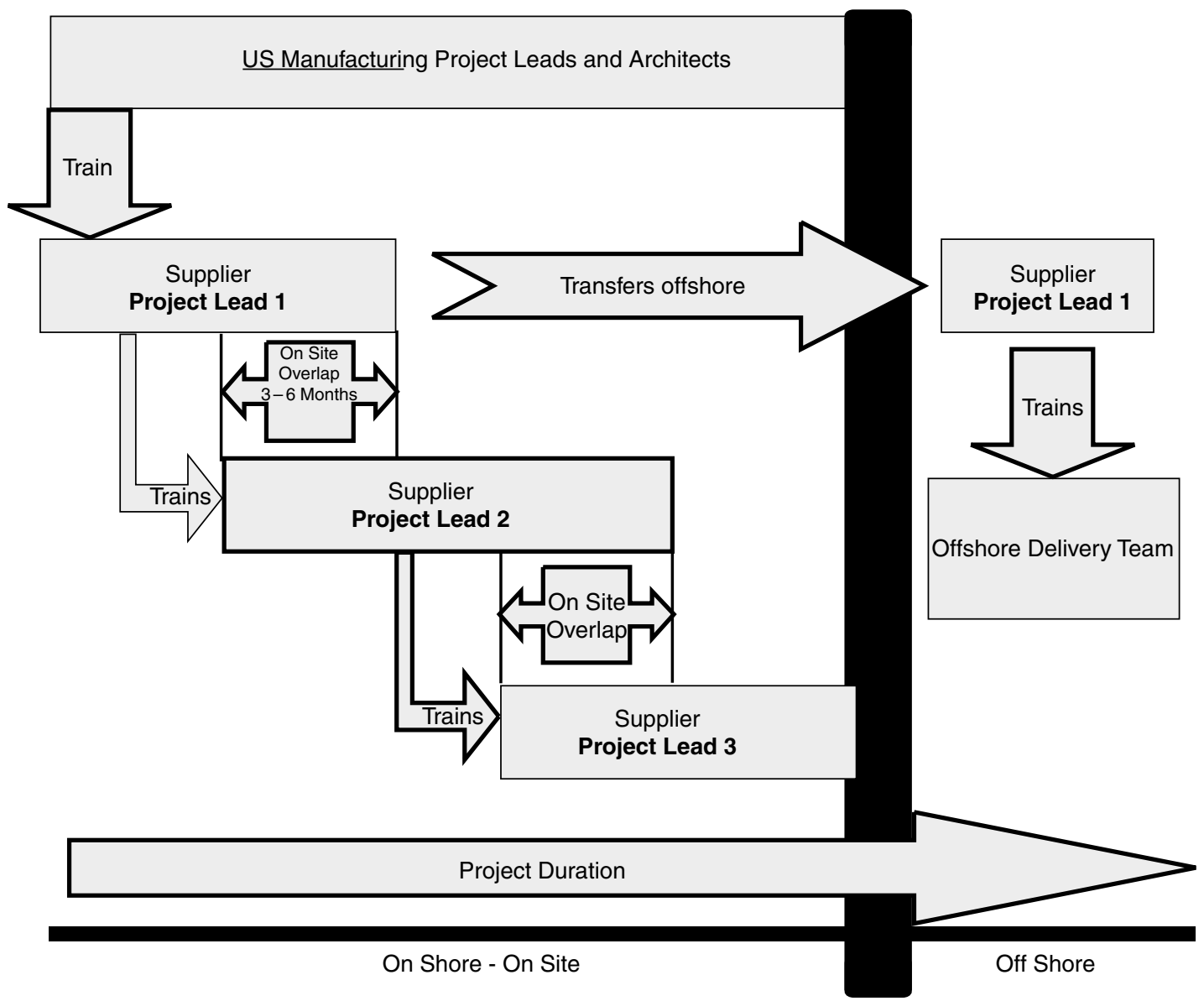

Figure 2 US Manufacturing use of supplier employee shadowing. 
to the achievement of network tasks and outcomes' (2005: 153). Within a strategic alliance involving a US customer and Indian suppliers, achieving a cultural understanding is key to successful knowledge transfer. Social norms and cultures can both positively and negatively affect the acceptance of a new idea or goal (Rogers, 2006). Furthermore, 'since partner firms usually have distinct cultures, strategic alliances are often formed on the basis of cultural compromise among the partners concerned. Cultural conflict will arise if certain partners rigidly push forward their own ways of doing things' (Inkpen and Tsang, 2005: 153). To help avoid these conflicts, US Manufacturing utilized four key practices detailed below.

Cognitive Dimension: Practice 4: Visit the offshore supplier and project teams to build personal connections and understand the offshore landscape

While on the surface, this practice seems obvious, it did not occur to the manager of the SCE for 2 years. The costs (financial, time, health concerns, etc.) often prevent US managers from visiting the Indian suppliers. When the manager of the SCE finally made the trip to Bangalore, India to visit the people he had worked with for 2 years, but had never met face to face, he realized the high value of the trip. During his 2-week trip, he visited both the large suppliers and the boutique firm.

I can't believe I waited two years to meet the people I have been only e-mailing and seeing in video conferences! What a difference this trip has made. Now I know my team. I should have done this at the very beginning. I now have faces, and more importantly personalities, to go with names and titles. This trip was worth every penny.

It was not only the meetings themselves that created the connections. Rather, face-to-face interactions allowed for a level of social interaction that was impossible during teleconferences or email conversations. The individuals were able to have casual conversations about families, shared experiences, even personal goals. Additionally, shared meals and social activities helped to cement the connection between US Manufacturing and their suppliers. These interactions represented 'informal socializing ties' (Oh et al., 2004) and, for US Manufacturing, increased the level of social capital.

Not only did the trip help US Manufacturing understand the culture of their suppliers, the reverse was true as well. US Manufacturing was able to communicate their goals and culture to the supplier. This sharing of both culture and goals enhanced the social capital and subsequently eased knowledge transfer. Additionally, it helped established the groundwork for future negotiations.

According to the Head of Delivery Excellence for US Manufacturing's large Indian supplier, 'It was wonderful to finally meet [the manager of the SCE]. So many things become clear when you meet face to face. Email and teleconferences don't let you get to know the person.'

Cognitive Dimension: Practice 5: Clarify goals by communicating the offshore strategy to all parties US Manufacturing, like most of the US client firms we studied, were using offshore outsourcing to 'do more with less.' US Manufacturing did not intend to reduce internal headcount through outsourcing, but planned to use offshore outsourcing to reduce the immense backlog of work. This message was strongly communicated to the internal IT staff, which assuaged their fears and made them more willing to cooperate with offshore suppliers. In addition, this message was shared with offshore suppliers so they did not have to worry about replacing US workers.

From the onset of its offshore effort, US Manufacturing took a transparent and well-communicated approach regarding its offshore strategy. To combat the then vitriolic national atmosphere toward offshore outsourcing and alleviate fears, US Manufacturing was very deliberate in their communications to the development staff. Considering that US Manufacturing did not intend to reduce internal headcount through outsourcing, but instead reduce workload, their message was more favorable than other outsourcing announcements. The plans to explore offshore outsourcing were met with optimism and relief by the internal staff of the SCE. Facing a 3-year backlog and a flat staffing forecast, employees welcomed the possibility of a decreased workload. According to the manager of the SCE,

My people were tired of working 60 hour weeks. We communicated that offshore was a way to better manage our project pipeline since we were not going to add a bunch of expensive North American resources to meet the demand and then lay them off later, we had to find other ways of being able to add flexibility to our workforce. And so they are not worried about losing their job. They just see this as a way of getting back to some kind of normal 40 to 50 hour workweek, and even more importantly, as a way for them to move up in their level of responsibility.

Communicating the goal of utilizing offshore as a way of managing the application backlog and not reducing development headcount helped the internal development staff to understand the goals of US Manufacturing and how they would impact their own careers and employment (see Practice eight). This created an atmosphere that enhanced the knowledge transfer effort. For example, according to the engineering supervisor,

I was amazed at how open our developers were with the supplier's team. Once they realized that the quicker they [the offshore team] were up to speed, the sooner they could share the load, there was no 'turf to protect, or 'secrets' to keep.

This practice was also evident in the relationship between US Manufacturing and the suppliers. The members of the SCE used an internally developed decision support system (this system is described in detail in Practice eight below) to actively manage headcount and inform the supplier of upcoming work. By being able to predict future revenue, the suppliers were able to focus developer efforts on production rather than revenue generation. According to the manager of the SCE,

Initially, the developers seemed to have one eye on the current project and one eye on 'what is coming next'. 
Once we were able to share our forecasts with them, the attention turned to the current tasks.

The suppliers shared in the benefits of this practice. According to the on-site engagement manager, 'My job is made easier by having the project forecasts from [US Manufacturing]. While the largest part of my job is the current engagement, there is an expectation from my superiors to look for additional opportunities. Since they share with me the plan, I can spend more time on what is to be done now.'

The successful use of this practice also confirms the work of Inkpen and Tsang and the strategic aspect of the relationship US Manufacturing had with its suppliers. 'For strategic alliances we also expect that goal clarity reduces interpartner conflict by facilitating the negotiation and establishment of shared goals. When the objectives and strategies of an alliance are clearly stated, a foundation of common understanding and the means to achieve the collaborative purpose is established among the partners' (2005: 157).

\section{Cognitive Dimension: Practice 6: Integrate the offshore} employees fully into the development team

One way to encourage knowledge transfer is the enhancement of social relationships (Oh et al., 2004). Many firms find it difficult to integrate the supplier's employees into the culture and social systems of their firms. Our research shows that offshore suppliers are often viewed with fear and even contempt. For example, the program managers at one Fortune 100 firm we investigated witnessed open hostility between offshore system administrators and business units who would have never engaged in such unprofessional behavior with internal employees.

US Manufacturing made a concerted effort to encourage and facilitate integration. This integration was not limited to training or knowledge transfer. It helped to create a team atmosphere that lasts even after the supplier's employees are transferred offshore. According to the manager of the SCE,

When we bring these offshore people in for training, they sit with the people who will be doing the work just like them. They're in the meeting learning about all this stuff and being mentored by the leads on a pretty personal basis for the most part. And I think the fact that we value diversity and try to encourage that and that we try not to build walls among the people who are here helped to foster the building of those relationships. We make sure that the vendor's employees are invited to birthday parties and happy hours. It helps for the teams to come together.

This effort to increase the social capital between internal and supplier employees paid dividends at US Manufacturing. The line between ' $u$ s and them' blurred and the suppliers' employees (both on and offshore) were viewed by US Manufacturing employees as team members and they all shared in the successes and challenges of the projects.
According to the Group Project Manager at one of US Manufacturing's large Indian suppliers,

Of all of our embedded systems clients, [US Manufacturing] has worked the hardest to make our employees feel very much part of the team at [US Manufacturing]. Our C-Sat (customer satisfaction ratings) from [US Manufacturing] show the value of this integration. Our employees have internalized the mission and values of [US Manufacturing]. It is a highly coveted assignment to work on the [US Manufacturing] account.

Cognitive Dimension: Practice 7: Synchronize the training of offshore employees with internal training efforts

While the co-training of internal employees with supplier employees creates significant trade secret and intellectual property risks, the SCE felt it was necessary. Owing to significant amounts of product and process knowledge the suppliers needed to successfully develop software, and the need to foster common goals among all developers, the SCE chose to co-train both internal and supplier developers.

The SCE provided the key supplier employees with facility tours and training classes on engine architecture, production software, equipment simulation products, operating guides for various lines of equipment, quality assurance processes, and an overview of all of the various manufacturing products and platforms. They were introduced to various software development tools, the development environment and embedded development tools.

These classes were delivered on site and in person to the suppliers' on-site employees. The SCE paid the supplier employees for the time spent in training, but it only paid offshore ( $v s$ the much higher on-shore) rates.

For the offshore developers, the classes were recorded and streamed offshore. According to the manager of the SCE:

We couldn't ship an engine or a piece of large equipment over to India, so we did the next best thing: we videotaped many equipment pieces in action and showed what the ECUs (Electronic Control Units) were designed to do.

In addition, the SCE invited most of the employees of the offshore suppliers to spend some time on-site prior to working on the outsourced projects. According to the Manager of the SCE:

What we saw was the benefit and real value of actually bringing those people here for a short time to bring them up to speed. Let them see how an application works and work right next to the team doing the development.

Relational Dimension: Practice 8: Increase internal trust by demonstrating how offshore outsourcing will improve internal career paths

Trust has been discussed widely in the management arena. Specifically, the use of rewards (Ferrin and Dirks, 2003), communication frequency (Becerra and Gupta, 2003), trust factors related to offshore development success (Jennex and Adelakun, 2003), electronic data interchange (Hart and Saunders, 1998), and inter-organizational trust (Zaheer et al., 1998) have shed light on various facets of organizational 
trust. In the context of this case, we focus on the role of trust in a network setting. It is vital that both parties in the alliance have sufficient trust to share knowledge and the allies are not viewed at competitors (Inkpen and Tsang, 2005).

To foster the trust of internal employees had in upper management's sourcing plans, the SCE clearly communicated the effects that offshore outsourcing would have on internal career paths.

To understand and communicate how the use of offshore outsourcing would affect the career paths of internal employees, US Manufacturing analyzed its internal human resource systems and project pipeline to better understand how to manage its workforce. This helped to create a positive 'shadow of the future' at US Manufacturing. From past experience, SCE managers knew that about one-third of programmers are promoted to higher value roles. For example, if SCE managers project that they will need five architects in 3 years time, they hire 15 new programmers internally. Even though these internal programmers cost considerably more than offshore equivalents, the SCE managers knew they needed to provide entry-level experiences to groom future IT leaders. According to the Engineering Supervisor,

We have made the business case to management that even though internal programmers are not as cost efficient as sourced programmers, we need to maintain a certain level of expertise internally.

As suggested by this practice, the SCE needed an accurate forecast of future IT needs. To accurately predict the human resources (HR) demand requires significant knowledge of the HR environment, past $H R$ trends and the current staffing constraints. US Manufacturing created an intricate staffing model that used as inputs the current and past project staffing data, the current internal talent pool and the projected demand. The rules for the system integrated 10 years of staffing history within the SCE and allowed for significant flexibility.

The staffing plan was openly communicated to both internal IT staff and suppliers. By communicating the plan with internal IT staff, US Manufacturing's developers were not worried that they were 'building their own guillotines' by working closely with the suppliers' teams. Instead, trust was established and enhanced by the internal employees seeing a clear and obtainable career path. By communicating the plan with offshore suppliers, the offshore suppliers could better plan for its staffing needs and better predict its future revenue generation. Such predictability enabled suppliers to stop selling and start working.

This trust was also evident from the supplier's perspective. According to the supplier's Group Project Manager for the US Manufacturing account:

Of all of our clients in the embedded software space [US Manufacturing] gives us the best picture of what is coming down the road. We use their forecasts to help us with our forecasts and can better predict how the account will grow.

The open communication of the vibrant internal career path and long-term commitment to suppliers laid the foundation for trust among the parties. Both sides saw the benefit of the relationship. As predicted by theory, the atmosphere of trust contributed to the free exchange of knowledge between committed exchange partners (Lin, 2007).

Additionally, researchers have identified separate types of trust. Namely, companion trust, competence trust, and commitment trust (Newell and Swan, 2000). In the case of US Manufacturing, commitment trust, which is 'central in proprietary networks where financial, property, or intellectual rights of the network relationships are at least partly defined' (Newell and Swan, 2000: 1295), represented the type of trust needed for fostering knowledge transfer. It was this type of trust that allowed the internal teams to fully engage the offshore teams without fear of damaging their own career goals. By reducing uncertainty, commitment trust was increased. US Manufacturing realized that if their second attempt was to succeed, internal employees needed to see and understand their future roles within US Manufacturing.

US Manufacturing is not alone in its desire to understand and predict the career paths of their IT employees. The 2004 survey of CIOs by the Society of Information Management (SIM) cited 'Attracting, developing and retaining IT professionals' as the second most important issue facing IS executives in 2004 (Luftman, 2005). The facilitation of growth by internal employees was a key feature in the development of the offshore models in round two. US Manufacturing placed significant value on grooming their IT architects and project leads internally and rewarding experience and loyalty. According to the Manager of the SCE,

We are now looking downstream in our pipeline and asking, 'Based on our projected demand and the projects we know we'll be undertaking, we know how many architects, project leads and how many programmers will be needed in 3-5 years ?' We then will use that data and determine, if we will need 5 architects in 3 years and we know from our past experience that one out of every 3 internal programmers makes it to architect; we know that we need to hire 15 programmers in order to 'grow' enough architects, because we do not use vendor's employees as architects. We have made the business case to management that even though internal programmers are not as cost efficient as sourced programmers, we need to maintain a certain level of expertise internally.

\section{Implications for researchers and practitioners}

While many researchers have studied both social capital and knowledge transfer, few have put forth specific practices that improved social capital and eased the knowledge transfer process. While additional research is needed to determine how various social capital and knowledge transfer practices are generalizable across firms and industries, the current study does show the importance in understanding both successful and unsuccessful offshore engagements through the lens of social capital. In the case of US Manufacturing, while the nurturing of social capital was not a sufficient lever for success, it was a necessary one. 
Practitioners, both on the customer and supplier side of offshore engagements, should find evidence of the need to address both social capital and knowledge transfer issues within their engagements. While many suppliers place considerable weight in CMM and CMMi certifications and processes (Adler and Kwon, 2002), this case shows that strong relationships and connections between the people involved are also critical to success. While transactions costs and intellectual property concerns do increase as both social capital and knowledge transfer increase, practitioners should develop a proper balance to ensure that cohesive and well-connected teams are able to form and pertinent knowledge and experiences are able to be transferred from customer to supplier.

\section{Conclusion}

US Manufacturing faced significant challenges in the offshore outsourcing of embedded software development. These challenges were significant enough that their first attempt failed to produce any acceptable deliverables. Moving forward from that failure, they developed eight practices that facilitated effective knowledge transfer. Using a social capital network model, this paper posits that those practices were effective because they increased the social capital between US Manufacturing and its suppliers. Managing the relationship at the structural, cognitive, and relational dimensions allowed the partners in the strategic alliance to increase network stability, reduce cultural barriers, share and understand common goals, and strengthen network ties.

\section{Note}

1 CIO Magazine reported in 2003 that savings may not be realized because the transaction costs (vendor selection, transitioning work, layoffs and retention, lost productivity, additional processes, and managing the contract) of offshore outsourcing can be as high as eight times the cost of the offshore labor.

\section{References}

Adler, P.S. and Kwon, S.-W. (2002). Social Capital: Prospects for a new concept, Academy of Management Review 27(1): 17-40.

Anand, V., Click, W. and Manz, C. (2002). Thriving on the Knowledge of Outsiders: Tapping organizational social capital, The Academy of Management Executive 16(1): 87.

Argote, L. and Ingram, P. (2000). Knowledge Transfer: A basis for competitive advantage in firms, Organizational Behavior and Human Decision Processes 82: $150-169$

Aron, R. and Singh, J. (2005). Getting Offshoring Right, Harvard Business Review 8(12): 135-143.

Beal, B. (2004). Survey Shows Satisfaction with Offshore Outsourcing, available on: http://searchcio.techtarget.com/originalContent/0,289142,sid19_ gci949702,00.html (accessed 10th February 2004).

Becerra, M. and Gupta, A. (2003). Perceived Trustworthiness within the Organization: The moderating impact of communication frequency on trustor and trustee effects, Organization Science 14(1): 32-44.

Burrell, G. and Morgan, G. (1979). Sociological Paradigms and Organizational Analysis, New Hampshire: Heinemann Educational Books (reprinted 1988).

Carter, T. (2006). Cheaper's Not Always Better, Dr. Dobb's Journal, available on: http://www.ddj.com/184415486.

Chowdhury, S. (2005). The Role of Affect- and Cognition-Based Trust in Complex Knowledge Sharing, Journal of Managerial Issues 17(3): 310-326.

Dess, G. and Shaw, J. (2001). Voluntary Turnover, Social Capital, and Organizational Performance, Academy of Management. The Academy of Management Review 26(3): 446-457.
DiamondCluster (2005). 2005 Global IT Outsourcing Study, available on: http:// www.diamondcluster.com/Ideas/Viewpoint/PDF/

DiamondCluster2005OutsourcingStudy.pdf.

Ferrin, D. and Dirks, K. (2003). The Use of Rewards to Increase and Decrease Trust: Mediating processes and differential effects, Organization Science 14: $18-31$.

Granovetter, M. (1973). The Strength of Weak Ties, American Journal of Sociology 78(6): 1360-1380.

Gulati, R. (1995). Does Familiarity Breed Trust? The Implications of Repeated Ties for Contractual Choice in Alliances, Academy of Management Journal 38(1): 85-112.

Hagedoorn, J., Cloodt, D. and Van Kranenburg, H. (2006). The Strength Of R\&D Network Ties In High-Tech Industries - A Multi-Dimensional Analysis of the Effects of Tie Strength on Technological Performance, DRUID Summer Conference 2006, Copenhagen, Denmark, June 18-20, 2006. Available: http://www2.druid.dk/conferences/viewabstract.php?id=39\&cf=8.

Hansen, M. (1999). The Search-Transfer Problem: The role of weak ties in sharing knowledge across organization subunits, Administrative Science Quarterly 44(1): 82-111.

Hart, P. and Saunders, C. (1998). Emerging Electronic Partnerships: Antecedents and dimensions of EDI use from the supplier's perspective, Journal of Management Information Systems 14(4): 87-112.

Hatch, P. (2005). Offshore 2005 Research, Ventoro: Ver. 1.2.5.

Hofstede, G. (2001). Culture's Consequences, 2nd edn, Beverly Hills: Sage.

Inkpen, A. and Tsang, E. (2005). Social Capital Networks and Knowledge Transfer, Academy of Management Review 30(1): 146-165.

Jarvenpaa, S.L., Knoll, K. and Leidner, D.E. (1998). Is Anybody Out There? Antecedents of Trust in Global Virtual Teams, Journal of Management Information Systems 14(4): 29-64.

Jennex, M. and Adelakun, O. (2003). Success Factors for Offshore Information System Development, Journal of Information Technology Cases and Applications 5(3): 12-36.

Klein, H. and Myers, M. (1999). A Set of Principals for Conducting and Evaluating Interpretive Field Studies in Information Systems, MIS Quarterly 23(1): 67-94.

Koka, B. and Prescott, J. (2002). Strategic Alliances as Social Capital: A multidimensional view, Strategic Management Journal 23: 795-816.

Lacity, M. and Rottman, J. (2008). Offshore Outsourcing of IT Work, United Kingdom: Palgrave.

Levin, D. and Cross, R. (2004). The Strength of Weak Ties You Can Trust: The mediating role of trust in effective knowledge transfer, Management Science 50(11): 1477-1490.

Levina, N. and Vaast, E. (2005). The Emergence of Boundary Spanning Competence in Practice: Implications for implementation and use of information systems, MIS Quarterly 29(2): 235-363.

Lin, C. (2007). To Share or Not to Share: Modeling tacit knowledge sharing: Its mediators and antecedents, Journal of Business Ethics 70: 411-428.

Luftman, J. (2005). Key Issues for IT Executives 2004, MIS Quarterly Executive 4(2): 269-285.

McFadyen, M. and Cannella, A. (2004). Social Capital and Knowledge Creation: Diminishing returns of the number and strength of exchange relationships, Academy of Management Journal 47(5): 735-746.

McFarlan, F. and Nolan, R. (1995). How to Manage an IT Outsourcing Alliance, Sloan Management Review 36(2): 9-23.

Nahapiet, J. and Ghoshal, S. (1998). Social Capital, Intellectual Capital and the Organizational Advantage, Academy of Management 23(2): 242-266.

Newell, S. and Swan, J. (2000). Trust and Inter-Organizational Networking, Human Relations 53(10): 287-1328.

Oh, H., Chung, M-H. and Labianca, G. (2004). Group Social Capital and Group Effectiveness: The role of informal socializing ties, Academy of Management Journal 47(8): 860-875.

Oh, H., Labianca, G. and Chung, M.-H. (2006). A Multilevel Model of Group Social Capital, The Academy of Management Review 31(3): 569.

Orlikowski, W. and Baroudi, J. (1991). Studying Information Technology in Organizations: Research approaches and assumptions, Information Systems Research 2(1): 1-28.

Orr, J. (1996). Thinking About Machines, London: Cornell University Press.

Politis, J.D. (2003). The Connection between Trust and Knowledge Management: What are its implications for team performance, Journal of Knowledge Management 7(5): 55-66.

Rogers, E.M. (2006). Diffusion of Innovations, 5th edn, New York: Free Press. 
Rottman, J. (2006). Successfully Outsourcing Embedded Software Development, IEEE Computer 39(1): 55-61.

Rottman, J. and Lacity, M. (2004). Twenty Practices for Offshore Sourcing, MIS Quarterly Executive 3(3): 117-130.

Rottman, J. and Lacity, M. (2006a). Proven Practices for Effectively Offshoring IT Work, Sloan Management Review 47(3): 56-63.

Rottman, J. and Lacity, M. (2006b). Knowledge Transfer is the Key to Successful Strategic Outsourcing, The Outsourcing Project, Vol. 4, Chapter 1, July, 2006. Available: http://www.cxoeurope.com/documents.asp?d_ID $=87$.

Shaw, J., Duffy, M., Johnson, J. and Lockhart, D. (2005). Turnover, Social Capital Losses, and Performance, Academy of Management Journal 48(4): 594-625.

Tiwana, A. and Keil, M. (2007). Does Peripheral Knowledge Complement Control? An Empirical Test in Technology Outsourcing Alliances, Strategic Management Journal 28: 623-624.

Trompenaars, F. and Hampden-Turner, C. (1998). Riding The Waves Of Culture, London: Nicholas Brearley.

Tsai, W. (2001). Knowledge Transfer in Intraorganizational Networks: Effects of network position and absorptive capacity on business unit innovation and performance, Academy of Management Journal 44(5): 996-1005.

Tsoukas, H. (1996). The Firm as a Distributed Knowledge System: A constructionist approach, Strategic Management Journal 17(Special Issue): $11-25$.

Walsham, G. (1995). Interpretive Case Studies in IS Research: Nature and method, European Journal of Information Systems 4(4): 74-81.

Zaheer, A., McEvily, B. and Perrone, V. (1998). Does Trust Matter? Exploring the Effects of Interorganizational and Interpersonal Trust on Performance, Organization Science 9(2): 141-159.
Zineldin, M. and Bredenlow, T. (2003). Strategic Alliances: Synergies and challenges. A case of strategic outsourcing relationship "SOUR", International Journal of Physical Distribution \& Logistics Management 33(5): 449-463.

\section{About the author}

Dr. Joseph William Rottman is an assistant professor of Information Systems at the University of Missouri-St. Louis. He earned his Doctor of Science in Information Management from Washington University. He has conducted research and has spoken internationally on global sourcing, innovation diffusion, and public sector IT. He has been engaged by Fortune 500 companies to assess their global sourcing strategies as well as public sector organizations seeking strategic leadership. His publications have appeared in the Sloan Management Review, IEEE Computer, MIS Quarterly Executive, Journal of Information Technology, Information Systems Frontiers, and Information and Management. He is on the Editorial Board for MIS Quarterly Executive, Senior Editor (USA/Americas) for the Journal of Information Technology and a Fellow with the Center for International Studies at the University of Missouri-St. Louis. 